\title{
Remembering the Launch of JQC, 1985-1991
}

\author{
James Alan Fox
}

Published online: 12 October 2010

(C) Springer Science+Business Media, LLC 2010

Back in 1903 at Kitty Hawk, North Carolina, brothers Wilber and Orville Wright endured mockery and derision from their fair share of skeptics. "It will never get off the ground," they said of the Wright Brother's odd-looking contraption, wishfully named the Flyer. "Man is not meant to fly," insisted the critics. Of course, history proved the Wright doubters wrong.

The same was said back in 1983 about the idea for launching a journal devoted to quantitative criminology, though the story is hardly of legendary significance. A survey of nearly 100 leading criminologists at the time, soliciting their thoughts about the prospects for such an initiative, strongly voiced the opinion that the publication too would never fly. History also has proven them wrong.

What a difference a quarter century makes! The discipline of criminology, the existing body of research, and the toolkit of criminological research have changed dramatically since the March 1985 inaugural issue of the Journal of Quantitative Criminology. It wasn't very long ago that statistical methods were viewed by leaders of the field with a mix of fear and disdain, but now these tools are considered a virtual necessity. And, not that long ago, at the annual meeting of the American Society of Criminology, a prominent scholar who was serving as a panel discussant described statistics as "the black arts," refusing to comment on one presenter's paper just because it contained tables, charts and equations. Presently, entire panels at the ASC meetings are devoted to quantitative methods and applications.

My remembrances of the early years of the Journal of Quantitative Criminology are distant but distinct. As founding editor through the publication's fist 7 years, I constantly struggled with a pervasive degree of skepticism about the fledgling journal as well as the constant pressure to fill the quarterly page budget. Not only was I busy with the routine activities of editorship — assigning reviewers and playing referee on split decisions, but much of my time was devoted to recruiting potential contributors and submissions.

These were the pre-Internet days, when exposure was a function of the subscription base. The number of institutional subscribers grew, but much too slowly for my comfort

J. A. Fox $(\bowtie)$

Northeastern University, Boston, MA, USA

e-mail: j.fox@neu.edu 
level, as many academic libraries were reluctant to take on a new publication until it had proven its staying power. My constant challenge was to keep $J Q C$ alive and well, at least until I handed its stewardship onto the able hands of John Laub and then Michael Maltz, David McDowall, James Lynch and Alex Piquero who nourished the publication with new energy, new ideas and expansive networks.

In the early days of publication, I felt much like a salesman, routinely scouting out potential submissions at scholarly conferences. They weren't so much a "call for papers" as a "beg for papers." Unlike today, where the meeting program for the American Society of Criminology has multiple sessions devoted to various methodological issues and advances, back then there was rather little in the way of solid quantitative material, and what there was tended to be spread throughout the program. More important, new journals, like $J Q C$ was then, must always compete on an uneven playing field against the "big boys" like Criminology (the official publication of ASC), the Journal of Research in Crime and Delinquency, and the Journal of Criminal Law and Criminology, just to name a few.

In this competition, the field wasn't always tipped in our disfavor. From the start, JQC enjoyed some major selling points that would entice prospective authors. Most visible was the publication itself-its professional look and feel. Indeed, one of the reasons motivating the launch of $J Q C$ was the poor quality of many of the major journals (cheap paper and poor bindings that caused the pages to fall out). Plenum (the original publisher, which later morphed into Kluwer and then again into Springer) had long been regarded for its quality product.

More important than the appearance factor was the inability of the competitors' production companies to handle mathematical type and formulae. In the traditional journals, the Greek symbol $\chi^{2}$ was often printed as $\mathrm{X}^{2}$, and the mean was typically written as $\mathrm{M}$, instead of $\bar{X}$ because of the lack of overbar capability. And anything more than one level of subscript or superscript was simply not possible. Plenum, by contrast, because of its strong background in publishing scientific journals was quite adroit at copy-editing and typesetting complicated mathematics and complex tables.

Many existing journals, or many just their editors-in-chief, were resistant to publishing papers with a heavy dose of quantitative material. For example, one of the leading journals at the time noted in its instructions to prospective authors that tabular material should be kept at a minimum. It also tended to place most, if not all tables in the back of the article (and occasionally at the back of the entire issue) so they wouldn't be intrusive.

More than just the mundane matters of production were the composition of editorial boards and reviewer pools. $J Q C$ was designed, from the start, to be a publication by and for quantitative researchers. In the 1980s, of course, few mainstream and established criminologists fit this mold, and so JQC drew heavily from peripheral disciplines and scholars trained in economics, operations research, geography and, of course, statistics, yet held at least some substantive interest in studying issues of crime and justice. $J Q C$ also was an inviting forum for several quantitatively-skilled newcomers to the discipline, who, at least in part due to their $J Q C$ publications, have since become established leaders of the field.

One of the concerns expressed by early detractors was that $J Q C$ would appeal only to a small group of researchers, both in terms of contributors and readers, and that the pool of material would dry up in a matter of a few years. Not only has the record of success proven otherwise in terms of longevity, but the pages of $J Q C$ have featured a large and wide array of scholars.

During the first 25 years-and 100 issues, JQC printed 462 articles and research notes. This group represented the work of as many as 645 individuals and hardly the same people 
over and over again. As shown in Fig. 1, the vast majority of authors have appeared only once in $J Q C$, with a mean number of authorships per individual of only 1.53. As is common of the tail of most distributions, a few scholars have found $J Q C$ to be a welcoming outlet for their work on numerous occasions. In fact, 15 individuals, including two of $J Q C$ 's editors (but not during their terms of editorship) have contributed more than five publications, as sole authors or co-authors. In my mind, the $J Q C$ "frequent authorship club," identified in Table 1, deserves this small token of recognition but with a large measure of gratitude.

Despite the consensus early on that the pool of quantitative research studies was just too shallow to support the journal, JQC has had little trouble in filing its pages with high quality material. Figure 2 shows trends in the level of sophistication over the 25 years time frame from 1985 to 2009 . Admittedly subjective, so much so that a peer review might challenge its validity, papers were rated on a five-point scale, with one indicating mostly descriptive presentation of empirical data through five indicating an effort to advance the field methodologically. Aside from a dip here and there, the level of technical

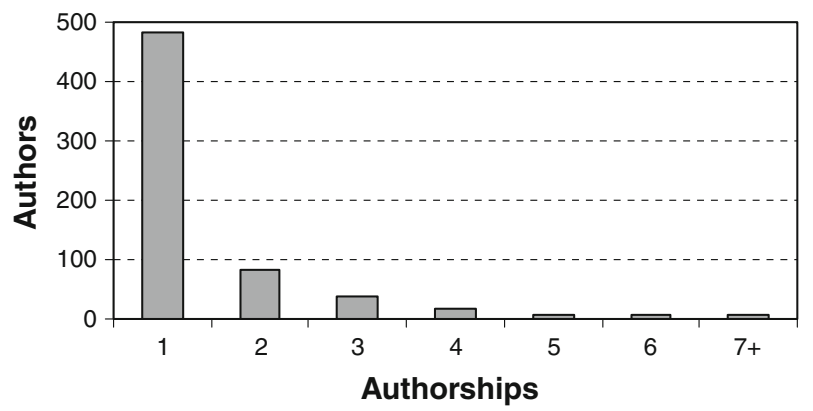

Fig. 1 Authorship frequencies

Table $1 J Q C$ top appearing authors

\begin{tabular}{lc}
\hline Author & Authorships \\
\hline Brame, R. & 13 \\
Paternoster, R. & 12 \\
Piquero, A. & 11 \\
Bushway, S. & 10 \\
Britt, C. & 7 \\
Nagin, D. & 7 \\
Tittle, C. & 7 \\
Albonetti, C. & 6 \\
Berk, R. & 6 \\
Cook, P. & 6 \\
Grasmick, H. & 6 \\
Laub, J. & 6 \\
Messner, S. & 6 \\
Pogarsky, G. & 6 \\
Wooldredge, J. & 6 \\
\hline
\end{tabular}




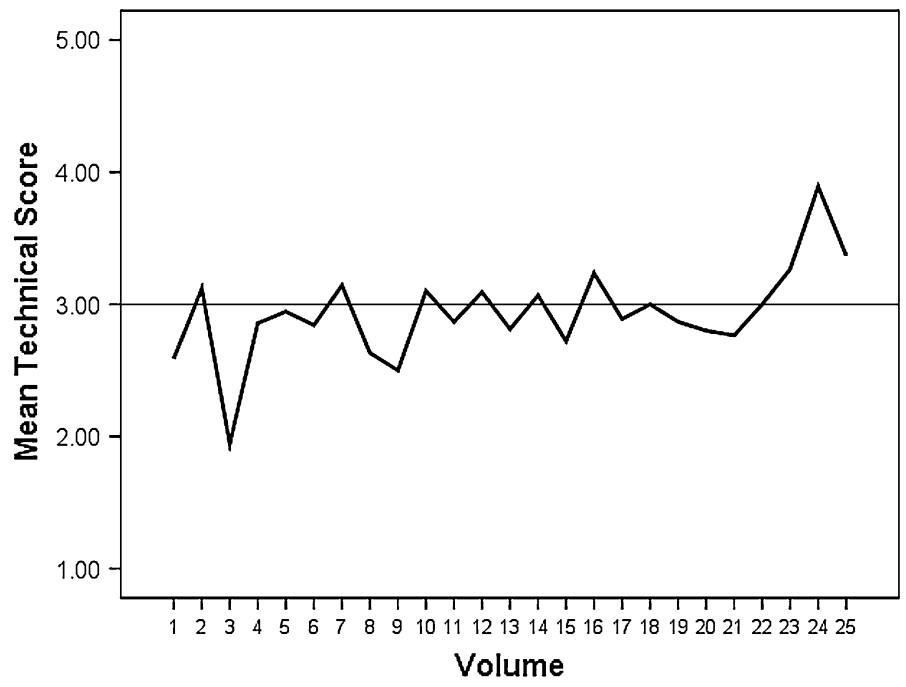

Fig. 2 Mean technical score by $J Q C$ volume

sophistication has remained fairly steady. Still, the figure reflects a modestly increasing secular trend over the years, owing again to the outstanding work of the editors who succeeded me and the hundreds who have graced $J Q C$ with their work.

To some extent, it seems like a lifetime since the launch of JQC. For me, it is nearly half of one. It has been a privilege to have been associated with this outstanding publication, and a source of great personal pride to see its growth, development, and rise in the rankings of journals in the field. I may have had the idea and planted the seed, but so much credit goes to those who have followed to help it grow and blossom. Yet, I also wish to acknowledge those who were instrumental in giving $J Q C$ its start and early momentum: my first team of associate editors, William Bowers and Paul Tracy, and the first editorial board of far too many to mention individually. Several editors at Plenum helped launch JQC, including Carol Bishop of the Journals Division, James Langlois of the Production Department, and especially Eliot Werner who had enough faith in the concept and confidence in me to sign the project.

I'm sure that the early struggles of $J Q C$ are not news to my successors as editor: Laub, Maltz, McDowall and Lynch. All were quite aware of and confronted the resistance to quantitative methods back in the 1980s. Alex Piquero, on the other hand, was only 14 when the inaugural issue was published, and probability didn't know a standard deviation from a standard transmission, Pythagoras from Monty Python.

Times change, and new generations take over. $J Q C$ has, I believe, been a major factor in helping to transform attitudes within the discipline about the value of quantitative research. And I trust that it will continue to set the standard of methodological excellence for many years to come. I may not be around to see the 50th year of $J Q C$ celebrated, but I am confident that the new breed of criminologists will help maintain JQC as a prominent and prestigious publication outlet for many years to come. 